\title{
O ENTRELAÇAMENTO DE LITERATURA E MEMÓRIA EM EXPERIÊNCIAS INTERDisCiPLinares de ENSINO de PoRTUguês E História
}

\author{
Ilse Leone Borges Chaves de Oliveira (Cepae/UFG)* \\ Andréa Ferreira Delgado (Cepae/UFG) ${ }^{* *}$
}

\begin{abstract}
Resumo
O artigo apresenta experiências interdisciplinares de ensino de Português e de História construídas, ao longo de cinco anos, a partir de práticas escolares de leitura. Entre essas, privilegiam-se aquelas em que realizamos a mediação didática a partir do entrelaçamento do campo teórico da memória com o da literatura. Discutimos concepçóes teóricas acerca da escrita da memória e delineamos os itinerários que percorremos na experiência "A construção afetiva da memória familiar" com o objetivo de associar a leitura de textos literários e de outros gêneros textuais com a prática de história oral e da produção de textos pelos alunos.
\end{abstract}

Palavras-Chave: literatura, memória, interdisciplinaridade, leitura escolar.

The interweaving of literature and memory in interdisciplinary experiences in the teaching of Portuguese and History

\section{Abstract}

This article presents interdisciplinary experiences in the teaching of Portuguese and History held during five years starting from reading practices. Among them, we privileged the ones that we mediated, interweaving the theoretical field of memory with the literature one. We discussed theoretical conceptions about the writing of memory and delineated the paths that we went through in the experience "An affective construction of familiar memory" with the aim of associating the reading of literary texts and other textual genders with the practice of oral history and texts produced by students.

KEY wORDs: literature, memory, interdisciplinarity, school reading.

Nossa prática de ensino de Português e História no Centro de Ensino e Pesquisa Aplicada à Educação, há cerca de cinco anos, está fundamentada na produção de itinerários interdisciplinares para a abordagem dos conteúdos. Nosso trabalho em sala de aula dialoga com dois projetos de pesquisa, que tem em comum a promoção da leitura no espaço escolar:

* Professora de Língua Portuguesa do Centro de Ensino e Pesquisa Aplicada à Educaçáo (Cepae/ UFG). Doutoranda em Estudos Linguísticos pela UFG. E-mail: ilseleone@yahoo.com.br.

** Professora de História do Centro de Ensino e Pesquisa Aplicada à Educação (Cepae/ UFG). Doutora em História pela Unicamp. E-mail: andreadelgado@uol.com.br. 


\section{Revista Solta a Voz, v. 19, n. 1}

o projeto "A prática social da leitura", do qual participa a professora de Português, e o projeto "Memória e literatura: a construção de experiências pedagógicas interdisciplinares", que nós duas - professoras de Português e de História - elaboramos, inter-relacionando a investigação teórica da escrita da memória com o desafio de realizar a transposição didática (Chevallard, 1991) na produção de textos e atividades para a prática pedagógica da leitura escolar e do estudo da história.

Como atividade associada à prática escolar, a leitura submete-se à ordem dessa instituiçâo (Cruvinel, 2002) e, exatamente por isso, nós acreditamos que é imprescindível tornar a leitura - essa imposta pela escola - uma atividade significativa e até mesmo prazerosa para os alunos. Compreendemos o ato de ler como

um processo abrangente e complexo; é um processo de compreensão, de intelecção de mundo que envolve uma característica essencial e singular ao homem: a sua capacidade simbólica e de interação com o outro pela mediaçáo da palavra (Brandáo e Micheletti, 2001, p. 17).

Se a leitura é um ato assim tão complexo, maior complexidade ainda atinge quando se trata do texto literário, essencialmente simbólico e polissêmico por natureza. É a força do discurso artístico estabelecendo entre o homem e o mundo uma ligação de mão dupla: por um lado, trabalha o intelecto, informa e produz conhecimento; por outro, desperta vivências íntimas, desencadeia e supre fantasias e emoçóes, levando o leitor a um processo de transformação interior.

No entanto, na escola - assim como nos demais espaços sociais não é fácil aproximar leitor e texto literário. Ainda mais difícil é conseguir que os alunos leiam, mesmo não gostando, e reconheçam o valor de um livro pelo trabalho artístico com a linguagem, pela realidade que esse trabalho (re)cria, identificando o leitor com a vida de outros.

O desafio de promover a leitura escolar nos instigou a desenvolver projetos interdisciplinares (Kleiman, 1999) que problematizam a experiência social dos alunos e alunas por meio de eixos temáticos - escola, família, alimentação e gênero -, na tentativa de diminuir a rejeição entre o aluno-leitor e o texto literário e transformar a leitura numa estimulante aventura de autoconhecimento e conhecimento do mundo.

Para alcançar esses objetivos, as premissas pedagógicas dessas práticas de leitura são a interdisciplinaridade e a contextualização, visando à 
produção de múltiplas estratégias capazes de diminuir a distância entre o texto literário e as vivências dos alunos.

Essa concepção do trabalho pedagógico constitui o fundamento tanto dos Parâmetros Curriculares Nacionais (Brasil, 2002) quanto das Diretrizes Curriculares Nacionais para o Ensino Médio (Brasil, 2002) elaborados, respectivamente, pelo Ministério da Educação e Conselho Nacional de Educação. Para superar a compartimentalização do ensino e a descontextualização do conhecimento escolar que têm provocado o desinteresse dos alunos e seu pouco envolvimento com a escola, propóe-se a "integração dos diferentes conhecimentos" a fim de criar condiçóes para "uma aprendizagem motivadora na medida em que ofereça maior liberdade aos professores e alunos para a seleção de conteúdos mais diretamente relacionados aos assuntos ou problemas que dizem respeito à comunidade" (Brasil/PCNEM, 2002, p. 32).

Como o nosso interesse é aproximar o aluno-leitor do texto literário para promover a aprendizagem significativa, precisamos contextualizar a prática de leitura a partir de "um referencial que permita aos alunos identificar e se identificar com as questóes propostas" (Brasil/PCNEM, 2002, p. 32). Por isso, consideramos que nada é mais pertinente do que trabalhar com eixos temáticos que associem as obras literárias ao cotidiano dos alunos, evocando constantemente "áreas, âmbitos ou dimensóes presentes na vida pessoal, social e cultural" que mobilizam competências cognitivas já adquiridas (Brasil/ DCNEM, 2002, p. 91).

Para trilhar esse caminho, a prática interdisciplinar se coloca como uma oportunidade privilegiada, uma vez que a abordagem da história na perspectiva da história cultural (Certeau, 1994; Hunt, 1992; Le Goff, 1990) guarda íntima afinidade com a Literatura. Os eixos temáticos são abordados em sala de aula, portanto, na perspectiva literária e histórica, pois associamos o trabalho artístico com a linguagem à historicização do cotidiano, a fim de colocar presente e passado em diálogo constante (Delgado e Oliveira, 2004).

A partir dos eixos temáticos selecionados, escolhemos textos literários que são considerados relevantes no contexto da produção literária nacional, por suas possibilidades expressivas e por permitirem tanto a reflexão de aspectos atemporais concernentes ao ser humano quanto a apreensão das experiências individuais e coletivas inscritas nas narrativas.

No projeto "Memória e literatura: a construção de experiências pedagógicas interdisciplinares", inter-relacionando a leitura à incorpora- 


\section{Revista Solta a Voz, v. 19, n. 1}

ção do estudo da memória como conteúdo escolar, objetivamos inserir na prática pedagógica a problematizaçâo do conceito de memória nas suas diferentes dimensóes: biográfica, coletiva, familiar. A partir da investigação teórica acerca da memória e da escrita da memória, ou seja, da produção da memória em diferentes gêneros literários, nosso desafio é realizar a mediação didática, na acepção de Alice Ribeiro Casimiro Lopes (1997a; 1997b). Em outras palavras, promover a construção de um conhecimento escolar acerca da memória, que didatiza o conhecimento científico sobre a memória, de forma necessariamente articulada com as experiências e os saberes daqueles grupos com os quais trabalhamos.

Como resultado dessa pesquisa, os projetos de ensino que construímos propóem uma abordagem da memória que transforma o conhecimento produzido em diferentes disciplinas acadêmicas em objeto de ensino. Um conjunto de procedimentos didáticos e metodológicos, além de questóes pertinentes à teoria da aprendizagem, deve ser levado em conta no processo de transformação de determinado objeto em saber escolar, tal como nos ensina Chervel (1990), ao propor a discussão da construção das disciplinas escolares.

Para apresentar os fundamentos teóricos do projeto que orientam as experiências pedagógicas, procuramos tecer os fios que associam a problematização da produção literária do passado com determinada epistemologia de compreensão da história.

Na discussão das especificidades do memorialismo enquanto gênero literário é recorrente a aproximação com a história, quando se estabelece o ater-se ao vivido como limite da criação literária do autor. Interessa-nos enfrentar essa discussão acerca das relaçóes entre a representação literária e a experiência vivida, promovendo a aproximaçáo com a discussão epistemológica da produçáo do conhecimento histórico. Num primeiro momento, vamos apresentar posiçôes de alguns críticos literários para, em seguida, apresentar nossa compreensão da escrita da memória.

Alfredo Bosi, no texto As "fronteiras da literatura" (1997), discute a escrita memorialística e evoca a "consciência do escritor" para estabelecer a fronteira "mínima" e "transparente" entre ficção e não-ficção. De um lado, o autor caracteriza o memorialista por meio da sua "consciência testemunhal" - "ele sabe que o objeto da sua escrita é a experiência, e é uma experiência que ele pode testar, empiricamente verificável: o real que aconteceu" (Bosi, 1997, p. 12). De outro, caracteriza o romancista e a produção 
da ficção - quando os fatos são trabalhados "por uma corrente subjetiva, filtrados, transformados” (Bosi, 1997, p. 13).

É exatamente no modo como o memorialista e o historiador trabalham que Bosi os aproxima, visto que a consciência testemunhal de ambos garante a fidelidade do texto ao real que aconteceu.

Posição semelhante é assumida por Joaquim Alves de Aguiar (1998, p. 22) ao afirmar que a situação do memorialista é marcada pela ambigüidade entre "a verdade e a ficção", dificultando o "enquadramento do escritor de memórias nos gêneros canônicos". Para este autor, essa posição dos memorialistas faz com que não tenham destaque nem no campo da literatura, nem no campo da história: de um lado, considera-se que a adesão ao retrato pode empobrecer o texto ficcional e, de outro lado, que o subjetivismo das impressóes é prejudicial à objetividade que se espera do historiador (Aguiar, 1998, p. 23).

Antonio Candido $(1956 ; 1989)$ discute a tensão presente no memorialismo, quando a utilização de recursos literários termina por ficcionalizar ou recriar o passado. Entretanto, à semelhança dos dois autores já mencionados, ele destaca como traço fundamental do gênero a verdade vivida no passado: nas suas palavras, "[...] sentimos sempre um certo esqueleto de realidade escorando os arrancos da fantasia" (Candido, 1956, p. 58).

Muitas das afirmaçóes de Bosi, Aguiar e Cândido podem ser contestadas a partir do campo da teoria da história que problematiza a crença na existência de um passado identificado com o "real que aconteceu", a ser desvelado pelo historiador. Em direção epistemológica oposta às concepçóes acima apresentadas, defende-se a impossibilidade de recuperação do passado tal como aconteceu, pois o ofício do historiador é subjetivo, ele filtra e transforma os dados empíricos na escrita da história, de tal forma que jamais produz um retrato do passado. Essa é a discussão historiográfica proposta por Paul Veyne (1983) e Hayden White (1994; 1995): o conhecimento histórico não pode ser pensado dissociado do texto produzido pelo historiador, aproximando história e literatura náo pelo estatuto da verdade presente no memorialismo, mas da ficcionalização promovida pela escritura do historiador. Partindo dessas premissas, vamos continuar a discussão acerca da escrita da memória, a fim de expor nossa concepção.

$\mathrm{Na}$ escrituração da memória, através da manipulação do passado pela imaginação criadora, o(a) autor(a) engendra a identidade por meio 
de estratégias discursivas que constroem, a um só tempo, o sujeito e o passado. Nesse processo de invenção de si, o autor é movido pelo desejo de criar uma imagem que corresponda à auto-interpretação e às expectativas do momento da escrita.

Alistair Thomson (1997) afirma que é a partir da identidade atual - da nossa percepçáo do que somos no momento e do que queremos ser - é que "compomos nossas reminiscências para dar sentido à nossa vida passada e presente" (Thomson, 1997, p. 56). No entanto, ao entregar-se à escrita da memória, o autor constrói, desconstrói e reconstrói incessantemente essa identidade.

Nas composições literárias que trabalham a memória no jogo da linguagem com o tempo, produz-se a identidade narrativa que, de acordo com as reflexões filosóficas de Paul Ricoeur (1994; 1997), não cessa de se fazer e se desfazer, considerando que ao reabrir o passado através do ato de rememoração, a escrita constrói incessantemente sentidos e significados novos, alterando a compreensáo do que foi vivido, do tempo presente e do futuro.

Aproximamo-nos, assim, da concepção de Walter Benjamin que compreende a escrita do rememorar enquanto tessitura do passado, pelos movimentos da memória e do esquecimento inscritos na vivência da multiplicidade temporal, instaurada no movimento pelo qual o sujeito, ao narrar-se no tempo, abre a própria vida para reconfiguraçóes infinitas - "um acontecimento vivido é finito, ou pelo menos encerrado na esfera do vivido, ao passo que um acontecimento lembrado é sem limites, porque é apenas uma chave para tudo o que veio antes e depois" (Benjamin, 1994, p. 37). Portanto, o tecer da rememoração compóe possibilidades infinitas de agenciamento de sentidos e significados para o passado, tanto para o próprio autor quanto para o leitor.

Michel Foucault (1992, p. 150) chama atenção para a complexidade da "escrita da si", gesto de "mostrar-se, dar-se a ver, fazer aparecer o rosto próprio junto", por meio da constante constituição e esfacelamento da identidade, nesse jogo da linguagem com o tempo.

Pelas consideraçóes tecidas até aqui já se vislumbra que, no estudo da escrita da memória, procuramos questionar aqueles que se prendem nas dicotomias texto-vida, texto-real, texto-verdade, por acreditar que a vida é inventada nas narrativas de si, que o real só é apreendido configurado na linguagem e que a vida, escrita pelo desejo, é sempre ficção. 
Essa concepção teórica orientou nossa leitura das obras memorialísticas e autobiográficas: não buscamos a correspondência direta com os eventos biográficos, nossa expectativa não foi a fusão entre texto e o conjunto de fatos empíricos que formam o passado vivenciado, pois estávamos interessadas em desvelar como os autores inventam a si mesmos na escrita da memória. No estudo das obras literárias, pretendemos, junto com nossos alunos e alunas, exercitar o "prazer do texto", na acepçáo de Roland Barthes tal como discutida por Leyla Perrone-Moisés (1983), acompanhando os autores no trabalho da memória que vai esculpindo a vida no tempo.

No projeto "Memória e literatura: a construção de experiências pedagógicas interdisciplinares", nosso objetivo principal foi investigar as conexões entre os mecanismos da memória e a criação literária, considerando as especificidades de cada gênero literário, com o intuito de construir experiências pedagógicas interdisciplinares de leitura e de produção de textos. Os itinerários metodológicos estão entrelaçados ao referencial teórico utilizado e entrecruzam literatura, história e procedimentos metodológicos da prática pedagógica do ensino de Português e de História.

Num primeiro momento, investigamos as obras selecionadas na tentativa de apreender as estratégias de construção da memória no processo de escrita de si, realizado por cada um(a) dos(as) autores(as). Para tanto, o estudo dos trabalhos dos críticos literários que analisam essas obras e traçam a trajetória dos autores, além de outros que refletem teoricamente sobre memória, memorialismo e autobiografia, constituiu-se num caminho fundamental da nossa trajetória de pesquisa.

No trabalho de sala de aula, a leitura da obra literária associava-se à abordagem interdisciplinar mais ampla do eixo temático em discussão tanto a investigação de múltiplas fontes históricas com objetivo de historicizar o cotidiano, quanto a um conjunto de textos literários e não literários que problematizassem práticas sociais do presente.

Para analisar as obras literárias, previamente lidas pelos alunos, produzimos textos didáticos visando trabalhar os mecanismos discursivos da escrita da memória. Esses textos foram elaborados a partir do estudo teórico do conceito de memória relacionado à criação literária.

Como estratégia pedagógica de leitura dos livros literários, propusemos um conjunto de atividades elaboradas a partir dos seguintes objetivos: associar a abordagem de aspectos teóricos da produção discursiva 


\section{Revista Solta a Voz, v. 19, n. 1}

da memória com a investigação da obra literária em estudo; relacionar os conteúdos do livro com a prática social dos alunos, problematizando constantemente tanto o passado inscrito no texto literário quanto o presente consubstanciado na sociedade contemporânea; analisar a intertextualidade estabelecida entre a obra literária e o conjunto de textos trabalhados em sala de aula e incentivar a produção de diferentes tipos de textos, inclusive narrativas biográficas (Oliveira e Delgado, 2006).

$\mathrm{Na}$ experiência que privilegiamos para discussão nesse texto, exploramos outra possibilidade de trabalho com a memória em sala de aula: a prática da história oral, pois como nos ensina Ecléa Bosi (2003, p. 15), “a memória oral é um instrumento precioso se desejamos constituir a crônica do cotidiano".

Ressaltamos que nossa abordagem da história oral no contexto escolar não se resume em propor entrevistas, tal como fazem muitos livros didáticos. Estimulamos os alunos a refletirem acerca do processo de entrevista e da produção de narrativas orais de cunho autobiográfico e memorialístico. Isto porque compreendemos o documento oral produzido no processo da entrevista, na interaçáo entre o pesquisador e o depoente, como outra modalidade discursiva de construção da memória que, como o texto literário, guarda especificidades que devem constituir objeto de investigaçóes tal como as realizadas por Ecléa Bosi (1987; 2003), Antonio Montenegro (1992), Michel Pollack (1989; 1992), Alessandro Portelli (1989), Alistair Thomson (1997) e Paul Thompson (1992).

$\mathrm{Na}$ caso da prática de história oral ressalta-se, ainda, o fato de se promover a interação social dos alunos. Os familiares de seu convívio e outras pessoas entrevistadas passam a ser considerados enquanto sujeitos históricos que podem contribuir na construção do conhecimento. Valorizam-se, assim, tanto as vivências pessoais dos adolescentes quanto as experiências dos grupos familiares - convidados a participar de diferentes projetos interdisciplinares.

Vamos a seguir apresentar como exemplo o projeto de ensino denominado "Memória e família: a construção afetiva do passado", planejado para trabalhar o tema "família", em duas turmas de sétimo ano, incorporando a história oral associada à prática de leitura.

Um livro, então, se impôs por sua pertinência com o tema, mas sobretudo pelo lirismo do seu enredo: Bisa Bia, Bisa Bel, de Ana Maria Machado (2002). Não se trata de um livro autobiográfico, no entanto ele foi escolhido justamente porque em sua trama se constrói a memória 
familiar a partir das aventuras da protagonista Isabel, a Bel, uma garotinha pré-adolescente, contemporânea nossa, que vai tecendo passado, presente e futuro numa narrativa que mistura a história de sua bisavó Bia, com sua própria história e a história de sua neta Beta.

Esses aspectos facilitam a identificação entre o leitor adolescente e o livro. Assim, o que se poderia considerar como complexidade do enredo, sua significação mais profunda e enigmática que é o diálogo entre passado, presente e futuro, torna-se, para o aluno-leitor, mais um desafio tentador que um empecilho para a leitura.

Vera Tietzmann Silva (1995) afirma, e concordamos com ela, que o núcleo temático central de Bisa Bia, Bisa Bel é a busca da identidade do pré-adolescente e que Ana Maria Machado optou pela busca de respostas incursionando no tempo. Vejamos, então, detalhadamente, como a autora manipula os mecanismos constitutivos da memória na construção do enredo.

Um dia, ao retornar da escola, Bel encontra a mãe mexendo numa caixinha de madeira cheia de fotografias. Sentada no chão, ao lado da mãe, ela acompanha o trabalho da memória: a mãe vai contando histórias suscitadas pelas fotografias. Entre essas, Bel encontra o retrato de uma menina:

Uma menininha linda, de cabelo todo cacheado. Vestido claro cheio de fitas e rendas, segurando numa das mãos uma boneca de chapéu e na outra uma espécie de pneu de bicicleta soltinho, sem bicicleta, sem raio, nem pedal, sei lá, uma coisa parecida com um bambolê de metal (Machado, 2002, p. 9).

Nesse fragmento, como estratégias de produção da narrativa, o retrato é descrito a partir da percepção da menina que, diante do objeto desconhecido, vai construindo aproximaçóes a partir de outros objetos que integram sua experiência.

A mãe identifica o retrato: é sua avó Beatriz, bisavó de Isabel, que a menina sequer conheceu. E identifica o objeto estranho: chamava-se arco, um brinquedo antigo - "Não é do meu tempo, é do tempo da vovó Beatriz. Sua bisavó... - minha mãe ia respondendo com uma voz meio sonhadora" (Machado, 2002, p. 10).

A mãe torna-se o primeiro elo com o passado, pois ela preservou o retrato e, tomando emprestadas outras memórias, é capaz de preencher as lacunas que possibilitam transformar os vestígios deixados pelo passado em conhecimento incorporado. Agora, cabe a Isabel continuar o trabalho da memória. 
Fiquei olhando aquele retrato e logo vi que não podia chamar de bisavó Beatriz aquela menina fofa com jeito de boneca. Não tinha cara nenhuma de bisavó, vê lá... Dava vontade de brincar com ela [...] Acho que deve ter sido meio por aí que comecei a pensar nela como minha Bisa Bia. E queria o retrato para mim. (Machado, 2002, p. 10)

É com a Bisa Bia ainda criança que Isabel se identifica tanto que começa a andar com a fotografia da bisavó por todos os lugares. Isabel sabe que Bisa Bia cresceu, se casou, envelheceu. E, apesar de se imaginar brincando com a Bisa menina, é com a Bisa velha que ela conversa.

Isabel passa então a se interessar pelo tempo de sua bisavó e, num diálogo com a memória dela, descobre um outro mundo, cheio de hábitos, costumes, objetos, comidas e modos de vestir diferentes dos seus. Bisa Bia também aprende sobre o tempo de Isabel. Elas são "capazes de ficar horas assim, batendo papo explicativo” (Machado, 2002, p. 26), uma explicando o seu próprio tempo para a outra. Até que um terceiro tempo se intromete no diálogo: é a Neta Beta, a bisneta de Isabel que vem antecipar o futuro. A partir de então, passado, presente e futuro estão amalgamados na narrativa.

O jogo com o tempo é mágico, mas verossímil. A habilidade da autora em tratar conceitos tão complexos como a relatividade do tempo e os conflitos de geraçóes, de maneira táo singela quanto poética, facilita o interesse dos alunos e a inserção deles na memória familiar.

A identidade de Isabel vai sendo construída no jogo de continuidade/rompimento com o passado, representado pela Bisa Bia, e de contestação do presente pelo futuro, personificado na Neta Beta. Se, na maior parte do tempo, o interesse e a curiosidade enredam Isabel e Bisa Bia, há também momentos de conflito. Quando Bisa Bia quer impor sua visão de mundo, a garota se rebela. No entanto, contraditoriamente, algumas atitudes demonstram que Isabel quer manter-se ligada ao passado. Por exemplo, quer aprender, por sugestão da bisavó, a bordar lenços como os que eram usados antigamente. Neta Beta vem interferir na história com um discurso avançado e libertário a que Isabel dá atenção apenas quando julga que não se contrapóe à sua própria vontade.

Nesse diálogo de múltiplos tempos, as contradiçóes percebidas na vivência da condição feminina é problematizada como parte constituinte da identidade. 
Mas também tem outra coisa: quando eu começo a ficar muito moderna, muito decidida, a me sentir muito forte e muito capaz de enfrentar tudo, às vezes me dá uma "recaída de bisavó", como Neta Beta chama. Quer dizer, quero dengo, descubro que sou fraca numas coisas, tenho vontade de pedir colo e procurar alguém que me ajude, passe a mão na minha cabeça e tome conta de mim um pouquinho. Não dá para ser mulher-maravilha. Pelo menos, náo dá o tempo todo, sem fingir. Vou descobrindo que dentro de mim é uma verdadeira salada. (Machado, 2002, p. 54)

Talvez os alunos também estejam vivenciando o duro aprendizado de conviver com essa "verdadeira salada" que existe dentro de cada adolescente e, por que não dizer, de cada um de nós. Afinal, tem sempre alguém por perto para dizer que fazemos parte de algo que existe muito antes de nós, tal como a família. Ao mesmo tempo, emerge o desejo de nos diferenciarmos, encontrar nossos próprios caminhos, realizar nossas experiências, como diz Bel numa passagem do livro. Vislumbramos, com sentimentos contraditórios, que estamos gestando a nós mesmos, ser singular que vai viver a vida e deixar os vestígios para o futuro - aqueles rastros que nossos bisnetos podem/devem encontrar. Nas palavras de Ana Maria Machado (2001, p. 62), no final do livro:

[...] eu também sou inventora, inventando todo dia um jeito novo de viver. $\mathrm{Eu}, \mathrm{Bel}$, uma trança de gente, igualzinho a quando faço uma trança no meu cabelo, divido em três partes e vou cruzando uma com as outras, a parte de mim mesma, a parte de Bisa Bia, a parte de Neta Beta. E Neta Beta vai fazer o mesmo comigo, a Bisa Bel dela, e com alguma bisneta que não dá nem para eu sonhar direito. E sempre assim. Cada vez melhor. Para cada um e para todo o mundo. Trança de gente.

A trança do tempo como obra de arte: passado, presente e futuro tão bem "entretrançados" na história-memória de Isabel que se identifica com a história-memória de todos nós. É a própria Ana Maria Machado (2001, p. 75) que afirma, em outra obra: "como todos os homens são semelhantes, eles acabam falando de verdades universais, de uma experiência compartida e de uma vivência comum. Isso é uma característica da arte: mergulhar tão fundo na diversidade individual que acaba chegando à universalidade”.

Vislumbram-se outras abordagens possíveis na prática da leitura escolar desse livro, além daquela da construção da memória familiar que 


\section{Revista Solta a Voz, v. 19, n. 1}

escolhemos trilhar com nossos alunos. Acreditamos que o passado da família é bastante instigante à curiosidade do adolescente, por ser parte integrante e constitutiva de sua identidade, ainda que disso ele possa não ter consciência.

Paralelamente à leitura de Bisa Bia, Bisa Bel, fizemos a leitura e discutimos a matéria "Por que preservar a memória familiar", publicada pela Folha de São Paulo, 05 jul. 2001, atendendo ao propósito de trabalhar com gêneros textuais diferentes, conforme orienta o projeto de ensino de Português. Nessa matéria, há depoimentos de algumas pessoas que se ocupam da reconstituição e da preservação da memória familiar, fazendo pesquisas, entrevistas, viagens; guardando fotos e outros tipos de documentos; escrevendo livros e criando sites na Internet.

Na seqüência, foi discutido na sala de aula de Português o texto "Memória e família: a construção afetiva do passado" (Delgado, 2005), que passou a nomear também o projeto que desenvolvíamos.

$\mathrm{Na}$ escrita desse texto, as experiências com a memória que os alunos e alunas tinham vivenciado nas leituras literárias promovidas até então Bisa Bia, Bisa Bel (Machado, 2002) e Doidinho (Rego, 1994) - são associadas às narrativas memorialísticas suscitadas nas entrevistas realizadas pelos alunos, no início do ano letivo, com pessoas idosas a respeito de escolas do passado. Ao mesmo tempo, sem planejar anteriormente, a professora de História trabalhou com suas memórias familiares e, por meio delas, apresentou uma personagem: sua avó, com as práticas de preservação da memória que empreendeu quando precisou desmanchar sua casa para ir morar com uma das filhas.

Dessa tessitura, emergiram, com tratamento didático, temas caros aos estudos da memória, mais precisamente da memória familiar, tal como investigada por Ecléa Bosi (1997): o envelhecimento e o trabalho com a memória; a noção de construção de um passado associado à identidade; a produção, a preservação e a transmissão da memória familiar; os objetos biográficos e outros suportes da memória.

No final do texto, foi feito um convite para que os alunos historiassem o passado familiar com o objetivo de montar um livro-mosaico, formado por múltiplas memórias afetivas. A primeira tarefa foi fazer, em conjunto com um membro da família, um levantamento, nos arquivos privados, à procura das fontes materiais, escritas e iconográficas que constituíssem o suporte da memória familiar. 
$\mathrm{Na}$ discussão dos resultados desse inventário, várias formas de preservação da memória familiar povoaram a sala de aula: montagem de álbuns de fotografias, conservação de objetos diversos, filmagens, produção de livros de registro, narração oral de histórias da família, realização de festas e reunióes tradicionais. Ou seja, os arquivos privados das famílias foram transformados em objetos de discussão no espaço escolar.

O próximo passo da investigação foi escolher, em conjunto com o familiar, entre os documentos selecionados, aquele considerado mais significativo da memória familiar. Aquele possível de desencadear narrativas associadas às pessoas e/ou aos acontecimentos, aos lugares e às práticas de convívio familiar, considerados representativos do passado que a família julga importante preservar e divulgar para as novas geraçóes.

Para compreender as práticas de produção e conservação da memória familiar e, principalmente, os significados atribuídos ao documento escolhido, os(as) alunos(as) entrevistaram uma pessoa da família que se responsabiliza pelo trabalho de construção da memória, a partir de um roteiro de questóes construído coletivamente em sala de aula.

As entrevistas foram problematizadas por meio de discussóes que propunham a reflexão sobre os caminhos e estratégias do rememorar na composição dos depoimentos orais. Também realizamos sessôes de fotos, quando os alunos levaram para a escola o documento de memória familiar - vestidos, certidóes de nascimento, fotografias, cartóes-postais, cartas, xícaras, toalha de mesa, oratório, entre outros - e participaram dos arranjos para composição da fotografia.

Logo em seguida, os alunos passaram para outra etapa: a produção de um texto narrativo que, além da trama construída pelos depoentes, também apresentasse a experiência do aluno no processo de entrevista e explorasse os significados atribuídos por cada família ao processo de produção e conservação da memória.

Os textos produzidos pelos alunos tiveram que passar por várias revisóes. Ao cotejar a entrevista com o texto, em muitos casos, foi sugerida a inserção de transcriçóes de trechos e a abordagem de aspectos que os alunos tinham suprimido. Também terminamos concluindo que, em muitos casos, valia a inclusão de aspectos, relativos às entrevistas, que os alunos tinham contado no relatório que produziram sobre as etapas da pesquisa. Enfim, podemos afirmar que fomos reconstruindo a proposta 
inicial a partir da própria experiência de discussáo em sala de aula e do trabalho coletivo com os textos dos alunos.

Nas narrativas produzidas pelos alunos a partir das entrevistas, se entrecruzaram múltiplos discursos: dos pais, mães, avós, dos filhos, netos que compartilharam memórias. Dessa trama, emerge a complexidade temporal que entrelaça passado, presente e futuro na tessitura dos significados das experiências familiares de produção, preservação e transmissão de memórias.

Essa experiência pedagógica interdisciplinar resultou na composição de um livro: na abertura apresentamos a experiência; os textos dos alunos, ilustrados com a fotografia do documento analisado, foram reunidos em três capítulos - fontes materiais, fontes iconográficas e fontes escritas; após, há dois textos: no primeiro, a professora de Português aborda a prática de leitura do livro Bisa Bia, Bisa Bel e, no segundo, a professora de História problematiza a construção da memória familiar na sociedade contemporânea a partir das entrevistas e narrativas construídas pelos alunos e alunas. A segunda parte resulta de um trabalho de pesquisa da memória familiar relacionada à alimentação, que realizamos com essas duas turmas no ano seguinte, também associando literatura e prática da história oral.

Esperamos ter despertado a curiosidade para o livro, pois nos limites desse texto, optamos por discutir os pressupostos epistemológicos e metodológicos da nossa prática pedagógica interdisciplinar, no contexto do ensino de Português e de História, em detrimento da apresentação detalhada dos resultados da pesquisa realizada pelos alunos. Porém, procuramos expor os elementos constitutivos dessa experiência de memória familiar que permitem problematizar os nossos objetivos ao empreendêla: nós procuramos combinar leitura literária, prática de história oral e produção de textos para proporcionar que cada aluno construísse, para o passado associado à construção da memória individual e familiar, sentidos e significados próprios.

Em outras palavras, procuramos suscitar reflexóes sobre a temporalidade que envolve a existência humana, condição necessária para que as pessoas concebam sua vida enquanto duração temporal dotada de sentido. As experiências de "dizer o tempo", expressão de Jeanne Marie Gagnebin (1997) para se referir às narrativas de construção do passado, só podem ser compreendidas enquanto trabalho que interliga, a um só tempo, o passado, o presente e o futuro do sujeito narrador. 


\section{REFERÊNCIAS}

AGUIAR, J. Espaços da memória - um estudo sobre Pedro Nava. São Paulo: Editora da Universidade de São Paulo / FAPESP, 1998.

BENJAMIN, W. Magia e técnica, arte e política: ensaios sobre literatura e história da cultura. Obras Escolhidas, Volume I. São Paulo: Brasiliense, 1994.

BOSI, A. As fronteiras da literatura. In: AGUIAR, F. (Org.). Gêneros de fronteira - cruzamentos entre o histórico e o literário. São Paulo: Xamã, 1997. p. 11-19.

BOSI, E. Memória e sociedade, lembranças de velhos. São Paulo: T. A. Queiroz, 1987.

. O tempo vivo da memória. Ensaios de psicologia social. São Paulo: Ateliê Editorial, 2003.

BRANDÃO, H. H. N.; MICHELETTI, G. Teoria e Prática da Leitura. In: CHIAPPINI, L. (Org.). Aprender e ensinar com textos didáticos e paradidáticos. São Paulo: Cortez, 2001. p. 17-30.

BRASIL. Ministério da Educação. Conselho Nacional de Educação. Parecer CEB n. 15/98. Diretrizes Curriculares para o Ensino Médio. In: . Parâmetros Curriculares Nacionais: Ensino Médio. Brasília: MEC/ SENTEC, 2002.

BRASIL. Ministério da Educação. Secretaria de Educação Média e Tecnológica. In: _. Parâmetros Curriculares Nacionais: Ensino Médio. Brasília: MEC/SENTEC, 2002.

CANDIDO, A. Fiç̧ão e confissão. Ensaios sobre a obra de Graciliano Ramos. Rio de Janeiro: Livraria José Olympio Editora, 1956. . A educação pela noite e outros ensaios. São Paulo: Ática, 1989.

CERTEAU, M. de. A invenção do cotidiano. Artes de fazer. Petrópolis: Vozes, 1994.

CHERVEL, A. História das disciplinas escolares: reflexões sobre um campo de pesquisa. Teoria \& Educação, Porto Alegre, v. 2, p. 177-229, 1990. 
CHEVALLARD, Y. La transposición didáctica: del saber sabio al saber enseñado. Argentina: Aique Grupo Editor AS, 1991.

CRUVINEL, M. de F. A leitura literária na escola: a palavra como um diálogo infinito. 2002. Tese (Doutorado em Lingüística) - Faculdade de Ciências e Letras, Universidade Estadual Paulista "Júlio de Mesquita Filho". Araraquara-SP, 2002.

DELGADO, A. F.; OLIVEIRA, I. L. B. C. A alimentação como prática cultural: uma experiência interdisciplinar de ensino de história e português. Solta a Voz, Goiânia, v. 15, p. 95-107, jul./dez. 2004.

DELGADO, A. F. "Memória e família: a construção afetiva do passado”. Texto didático de circulação restrita, Goiânia, 2005 (mimeo).

FOUCAULT, M. O que é um autor? Lisboa: Editora Passagens, 1992.

GAGNEBIN, J. M. Sete aulas sobre linguagem, memória e história. Rio de Janeiro: Imago, 1997.

HUNT, L. (Org.). A nova história cultural. São Paulo: Martins Fontes, 1992.

KLEIMAN, A. B. Leitura e interdisciplinaridade: tecendo redes nos projetos da escola. Campinas: Mercado Aberto, 1999.

LE GOFF, J. (Org.). A história nova. São Paulo: Martins Fontes, 1990.

LOPES, A. C. Conhecimento escolar: inter-relações com conhecimentos científicos e cotidianos. Contexto e Educação, Ijuí-RS, n. 45, p. 40-59, jan./ mar. 1997a.

- Conhecimento escolar: processos de seleção cultural e de mediação didática. Educação \& Realidade, Porto Alegre, n. 22, p. 95-111, jan./jun. 1997b.

MACHADO, A. M. Texturas: sobre leituras e escritos. Rio de Janeiro: Nova Fronteira, 2001.

. Bisa Bia, Bisa Bel. São Paulo: Moderna, 2002.

MONTENEGRO, A. T. História oral e Memória: a cultura popular revisitada. São Paulo: Contexto, 1992. 
OLIVEIRA, I. L. B. C. de; DELGADO, A. F. Memória e tessitura da narrativa: uma experiência escolar de leitura. Solta a Voz, Goiânia, v. 17, p. 119-133, jul./dez. 2006.

PERRONE-MOISÉS, L. Roland Barthes. São Paulo: Brasiliense, 1983.

POLLACK, M. Memória, esquecimento, silêncio. Estudos Históricos, Rio de Janeiro, v. 2, n. 3, p. 3-15, 1989.

. Memória e identidade social. Estudos Históricos, Rio de Janeiro, v. 5, n. 10, p. 200-12, 1992.

PORTELLI, A. Forma e significado na história oral. A pesquisa como um experimento em igualdade. Projeto História, n. 14, p. 7-39, 1989.

REGO, J. L. do. Doidinho. Rio de Janeiro: José Olympio, 1994.

RICOEUR, P. Tempo e narrativa (Tomo I). Campinas: Papirus, 1994. . Tempo e narrativa (Tomo III). Campinas: Papirus, 1997.

SILVA, V. T. Literatura infanto-juvenil: seis autores, seis estudos. Goiânia: UFG, 1995.

THOMPSON, P. A voz do passado: história oral. Rio de Janeiro: Paz e Terra, 1992.

THOMSON, A. Recompondo a memória: questôes sobre a relação entre história oral e as memórias. Projeto História, n. 15, p. 51-84, 1997.

VEYNE, P. Como se escreve a história. Lisboa: Ediçôes 70, 1983.

WHITE, H. Meta-História: a imaginação histórica do século XIX. São Paulo: Editora da Universidade de Sáo Paulo, 1995.

WHITE, H. Teoria Literária e escrita da história. Estudos Históricos, Rio de Janeiro, v. 7, n. 13, p. 21-48, 1994.

Recebido em:10 abr. 2008 Aceito em: 10 jun. 2008 